Running title: AGEs and insulin secretion

\title{
Advanced Glycation End Products (AGEs) are Cross- sectionally Associated with Insulin Secretion in Healthy
}

\section{Subjects.}

*Josephine M. Forbes ${ }^{\mathrm{a}, \mathrm{b}, \mathrm{c}}$, *Karly C. Sourris ${ }^{\mathrm{a}, \mathrm{h}}$, Maximilian P.J. de Courten $^{\mathrm{d}}$, Sonia L. Dougherty ${ }^{\mathrm{a}}$, Vibhasha Chand ${ }^{\mathrm{a}}$, Jasmine G. Lyons ${ }^{\mathrm{a}}$, David Bertovic ${ }^{\mathrm{a}}$, Markus P. Schlaich ${ }^{\mathrm{a}}$, Georgia Soldatos $^{\mathrm{a}}$, Mark E. Cooper ${ }^{\mathrm{a}, \mathrm{h}}$, Nora E. Straznicky ${ }^{\mathrm{a}}$, Bronwyn A. Kingwell ${ }^{\mathrm{a}}$, Barbora de Courten ${ }^{\mathrm{a}, \mathrm{f}, \mathrm{g}}$

${ }^{\mathrm{a}}$ Baker IDI Heart and Diabetes Institute, Melbourne, Australia

${ }^{b}$ Glycation and Diabetes, Mater Medical Research Institute, South Brisbane, Australia 
${ }^{c}$ School of Medicine, University of Queensland, St Lucia, Australia

${ }^{d}$ Copenhagen School of Global Health, Copenhagen University, Denmark

${ }^{e}$ Department of Medicine, (AH/NH) University of Melbourne, Austin Hospital, Heidelberg, Australia

${ }^{f}$ Department of Biomedical Sciences, Copenhagen University, Denmark

${ }^{g}$ Steno Diabetes Centre, Copenhagen, Denmark

${ }^{h}$ Departments of Medicine and Immunology, Central and Eastern Clinical School, AMREP Precinct, Monash University, Melbourne, Australia *These authors contributed equally to this manuscript

\section{Corresponding author:}

Prof Josephine Forbes

Mater Medical Research Institute

Translation Research Institute 
37 Kent Street,

Woolloongabba, QLD 4001

Telephone: +61734437642

Email: jforbes@mmri.mater.org.au

Word Count: (Must be 10 point Times New Roman Font as per ITO

Number of figures and tables: 2 tables, 1 figure

Keywords: insulin secretion, insulin sensitivity, central obesity, type 2 diabetes 


\section{Abstract}

It has been postulated that chronic exposure to high levels of advanced glycation end products (AGEs), in particular from dietary sources, can impair insulin secretion. In the present study, we investigated the cross-sectional relationship between AGEs and acute insulin secretion during an intravenous glucose tolerance test (IVGTT) and following a $75 \mathrm{~g}$ oral glucose tolerance test (OGTT) in healthy humans. We report the cross-sectional association between circulating AGE concentrations and insulin secretory function in healthy humans (17F:27M, aged $30 \pm 10 \mathrm{yrs}$ ) with a wide range of BMI $\left(24.6-31.0 \mathrm{~kg} / \mathrm{m}^{2}\right)$. Higher circulating concentrations of AGEs were related to increased first phase insulin secretion during IVGTT $(\mathrm{r}=0.43 ; \mathrm{p}<0.05)$ and lower 2-hour glucose concentrations during OGTT $(\mathrm{r}=-0.31 ; \mathrm{p}<0.05)$. In addition, fasting $(r=-0.36 ; \mathrm{p}<0.05)$ and 2-hour glucose concentrations were negatively related to circulating levels of soluble 
receptor for AGE (RAGE) isoforms $(r=-0.39 ; \mathrm{p}<0.01)$. In conclusion, in healthy humans, we show a cross-sectional association between advanced glycation end products and acute insulin secretion during glucose tolerance testing. 


\section{Abbreviations}

AGE - Advanced glycation end product

HOMA-IR - Homeostatic model of insulin resistance

RAGE - Receptor for advanced glycation end products

IVGTT - Intravenous glucose tolerance test

OGTT - Oral glucose tolerance test

PCNA - Proliferating cell nuclear antigen

RSA -Rat serum albumin

BMI - Body mass index 


\section{Introduction}

Insulin resistance and impaired insulin secretion the two major independent risk factors for type 2 diabetes (Weyer, Tataranni et al. 2001). Increased insulin secretion can develop as a primary defect or secondarily as a consequence of compensation for declining insulin sensitivity. In addition, abnormalities in insulin secretion play a central role in progression from impaired glucose tolerance (IGT) to type 2 diabetes (Pratley and Weyer 2002).

Diet represents an important environmental factor which can influence glycaemic control. Globalisation of the food chain has required changes in preparation techniques, which include the necessity to impart functional properties to food such as longer shelf life (Cordain, Eaton et al. 2005). Furthermore, increasing demands on family life and in some cases 
socioeconomic pressures have increased the utilization of more rapid cooking methods and hence the intake of highly processed "fast food". These changes have contributed to an increase in the consumption of foods containing increased amounts of advanced glycation end products (AGEs), which are important flavour and stabilization compounds in foods (Henle 2005). Studies have shown that there is uptake of a proportion of AGEs from the gut and despite efficient renal clearance, some AGEs are likely deposited in tissues (Vlassara, Striker et al. 1994, Miyata, Ueda et al. 1998, Hellwig, Geissler et al. 2009). Furthermore, there is preliminary evidence, primarily from animal models that increasing exposure to (Riboulet-Chavey, Pierron et al. 2006, Hagiwara, Gohda et al. 2009) or dietary intake of AGEs impairs insulin secretion and sensitivity (Hofmann, Dong et al. 2002, Sandu, Song et al. 2005, Coughlan and Forbes 2011, Forbes, Cowan et al. 2013). Excessive consumption of 
saturated fat and glucose can also promote advanced glycation (Beisswenger, Delucia et al. 2005, Sandu, Song et al. 2005, Forbes, Cowan et al. 2013). In cross-sectional human studies, higher circulating concentrations of AGE modified proteins are associated with diabetes, renal or cardiovascular disease (Stam, Schalkwijk et al. 2006, Nin, Jorsal et al. 2011) and acute changes in insulin secretion following meal challenges (Vaaler, Hanssen et al. 1984, Rizkalla, Laromiguiere et al. 2007). Intervention studies specifically demonstrate that increased AGE intake is associated with insulin resistance (Birlouez-Aragon, Saavedra et al. 2010, Uribarri, Cai et al. 2011) and macrovascular dysfunction (Uribarri, Stirban et al. 2007, Stirban, Kotsi et al. 2012). Conversely we and others have shown that individuals who are obese have lower circulating AGEs concentrations (Sebekova, Somoza et al. 2009, Sourris, Lyons et al. 2013). 
The receptor for advanced glycation end products (RAGE) is thought to bind to large ligands including AGE complexes (Tian, Avalos et al. 2007, Penfold, Coughlan et al. 2010) on cell surfaces and within the circulation (Zong, Madden et al. 2010) which has been associated with chronic disease (Schmidt, Yan et al. 1999, Yamamoto, Kato et al. 2001, Bierhaus, Haslbeck et al. 2004). We have recently shown that a chronic decline in the expression of RAGE is associated with a decline in insulin secretion and the development of experimental autoimmune diabetes and type 1 diabetes in children (Coughlan and Forbes 2011). In contrast however, some in vitro studies in isolated insulin producing cells lines have shown that acute exposure to AGEs can stimulate basal insulin secretion in the context of reduced glucose uptake (Kaneto, Fujii et al. 1996, Matsuoka, Kajimoto et al. 1997, 
Uribarri, Cai et al. 2011). These disparities in the relationship between AGEs and insulin secretion may relate to the duration or degree of exposure to excess AGE concentrations. Polymorphism in the AGER gene which encodes for RAGE has also been demonstrated to associate with insulin resistance in humans (Sullivan, Futers et al. 2005). To further examine whether there is a relationship between circulating AGEs and insulin secretion, we performed a cross-sectional analysis of circulating AGE modified albumin and direct measures of insulin secretion in healthy humans. 


\section{Materials and Methods}

\section{Human Clinical Study}

Volunteers were recruited (17 female, 27 male) between the ages of 18 and 50 years. Participants were non-diabetic, nonsmokers at the time of the study and generally healthy according to data obtained from detailed physical examination, basic laboratory analyses (fasting plasma lipid levels, liver function tests, urea, creatinine and electrolytes). No participant had signs of acute or chronic infection, or took any medication or illicit drugs. Height and weight were measured and body mass index (BMI) calculated. The protocol was approved by the Alfred Hospital Ethics Committee and complied with the Declaration of Helsinki. All participants provided written informed consent prior to participation.

Metabolic testing in humans 
At recruitment, an oral glucose tolerance test was performed after a $75 \mathrm{~g}$ oral glucose load (OGTT) where glucose tolerance was determined by WHO 1999 criteria. For three days before further metabolic testing, participants were asked to abstain from strenuous exercise and caffeine intake. The first metabolic testing day in females took place in their follicular phase. Insulin sensitivity and secretion were assessed after a 12-h overnight fast on 2 separate days. A hyperinsulinemiceuglycemic glucose clamp was performed as previously described to assess insulin sensitivity (Sourris, Lyons et al. 2009) In brief, a primed continuous intravenous infusion of insulin $(9 \mathrm{mU} / \mathrm{kg})$ was administered for $120 \mathrm{~min}$ at a constant rate of $40 \mathrm{mU} / \mathrm{m}^{2}$ body surface area per min. This infusion achieved plasma steady state insulin concentrations. Every 5 minutes during the clamp, plasma glucose was measured and the variable infusion of glucose adjusted in order to maintain blood glucose at a constant value of $5 \mathrm{mmol} / \mathrm{L}$. Finally, the 
rate of total insulin stimulated glucose disposal (M; $\mathrm{mg} / \mathrm{kg} / \mathrm{min}$ ) was calculated for the last $40 \mathrm{~min}$ of insulin infusion. In a subset of individuals $(n=22$; male 15: female 7), an intravenous glucose tolerance test (IVGTT) was then performed 7 days following the initial oral glucose tolerance test. The plasma increment of insulin at 3-5 minutes after the intravenous glucose bolus $(25 \mathrm{~g})$ was calculated as area under the curve (AUC).

\section{Biochemistry in Humans}

Plasma glucose concentrations were measured by the glucose oxidase method (ELM 105, Radiometer Copenhagen, Denmark). Plasma insulin levels were measured by chemiluminescent microparticle immunoassay. Serum was collected for analysis of AGEs using an indirect ELISA as previously described (Coughlan and Forbes 2011). Soluble RAGE (sRAGE) and endogenous secretory RAGE (esRAGE) 
were analysed in plasma samples using commercially available human sRAGE (R\&D Systems, Minneapolis, MN, USA) and esRAGE ELISAs (B-Bridge International, USA) (Penfold, Coughlan et al. 2010).

\section{Statistical Analyses}

Statistical analyses were performed using SAS Jump Statistics Software (Cary, North Carolina, USA). Results are given as mean \pm SD (unless otherwise indicated). Correlations were performed using the Spearman correlation coefficient. Multiple regression analyses were used to assess the determinants of insulin secretion after adjusting for covariates. Statistical significance was assumed when $\mathrm{p}<0.05$. 


\section{Results}

\section{AGEs and glucose metabolism in humans}

All participants were healthy according to the physical examination i.e. they were normotensive, had normal full blood counts, liver and renal function tests (data not shown). The study participants were $30 \pm 10$ years of age with an average BMI of $28 \pm 5 \mathrm{~kg} / \mathrm{m}^{2}$ (range: $24.6-31.4 \mathrm{~kg} / \mathrm{m}^{2}$ ) (Table 1) and a waist circumference of $93 \pm 13 \mathrm{~cm}$. Male participants were more overweight but were more insulin sensitive than female participants (Table 1). Fasting plasma glucose concentrations were not different between males and females but were slightly elevated outside the normal clinical range (Table 1). Two-hour plasma glucose concentrations during an OGTT were negatively related to increases in circulating AGE concentrations $(r=-0.31 ; p<0.05)$ (Table 2$)$. In the subgroup of 
22 individuals where acute insulin secretion during IVGTT measurement was available, early insulin secretory function was positively related to AGE concentrations $(r=0.43, p<0.05$; Table 2). Circulating AGE concentrations were a significant determinant of early insulin secretory function independently of age, gender, BMI and waist circumference $(p=0.03)$ and following additional adjustment for insulin sensitivity $(\mathrm{p}=0.01)$. Insulin sensitivity was not associated with serum AGE or circulating RAGE concentrations in this population (Table 2).

Circulating sRAGE and esRAGE concentrations were also inversely related to 2-hour plasma glucose concentrations during OGTT (Table 2). Fasting glucose was also negatively associated with circulating sRAGE concentrations (Table 2). There was a negative relationship between circulating sRAGE and fasting plasma insulin concentrations $(\mathrm{r}=0.36, \mathrm{p}=0.02)$, 
but no relationship with AGEs $(\mathrm{r}=0.23, \mathrm{p}=0.1)$ and esRAGE $(\mathrm{r}=-0.22, \mathrm{p}=0.2)$. 


\section{Discussion}

\section{Circulating AGEs associate with insulin secretion}

We have demonstrated a novel positive association between circulating fasting concentrations of advanced glycation end products and acute insulin secretion during IVGTT in healthy humans. Furthermore, 2-hour plasma glucose concentrations during an OGTT were negatively related to increases in circulating AGE concentrations. Circulating concentrations of soluble and esRAGE were negatively associated with 2-hour glucose concentrations and esRAGE with acute insulin secretion during IVGTT. Interestingly, correction for adiposity did not affect these associations between higher circulating levels of AGEs and acute insulin secretion during IVGTT or 2 hour glucoses following OGTT.

Other in vitro studies (Uribarri, Cai et al. 2011, Puddu, Sanguineti et al. 2012) and our own chronic rat feeding of 
AGEs for 24 weeks (Coughlan, Yap et al. 2011) have contrasted the present human study by suggesting that high concentrations of AGEs may impair glucose stimulated insulin secretion although these in vivo studies have been performed in lean male rats where there was no evidence of increased fat mass. Furthermore, in this previous in vivo study, we did not assess whether increases in AGEs firstly lead to enhanced compensatory insulin secretion at earlier time points following AGE exposure as might be seen in the compensatory phase of progressive injury to $\beta$-cells. Indeed, given that the individuals in the present study were healthy but many overweight, the association of AGEs with increases in insulin secretion may be indicative of hypersecretion of insulin in response to excess nutrient intake. Ultimately it is well understood that hyperinsulinemia due to compensation for increased obesity and insulin resistance, eventually progresses to a loss of first phase insulin secretion and type 2 
diabetes. This may be why dietary restriction of AGE intake has shown greater insulin secretion in individuals with type 2 diabetes with prominent $\beta$-cell abnormalities in first phase insulin secretion during IVGTT (Uribarri, Cai et al. 2011).

\section{Insulin resistance was not a determinant of AGE induced changes in insulin secretion}

Advanced glycation end products have been previously reported to influence insulin sensitivity. Within this healthy population studied, insulin resistance as determined by goldstandard hyperinsulinaemic-euglycaemic clamp did not associate with circulating AGE concentrations. There are other previous studies which have shown a negative relationship between circulating AGE concentrations and insulin sensitivity measured by HOMA in obese humans, where AGE concentrations were found to be lower with obesity (Sebekova, Somoza et al. 2009, Chiavaroli, D'Adamo 
et al. 2012). Furthermore, higher AGE concentrations were associated with higher acute phase insulin secretion in healthy but overweight humans in the present study, which could also be interpreted as improvements in $\beta$-cell function in the context of a glucose challenge. This discordance between circulating AGE concentrations, insulin sensitivity and glycaemic control warrants further investigation.

\section{AGEs show an inverse relationship with circulating $R A G E$ isoforms in overweight humans}

Advanced glycation end products can exert their physiological actions via receptors such as RAGE. There have been a number of previous in vitro studies suggesting that interruption of RAGE signalling can increase insulin secretion and decrease excess formation of reactive oxygen species following treatment with AGEs in cell lines (Uribarri, Cai et al. 2011, Puddu, Sanguineti et al. 2012). In more chronic 
progressive models however, it appears that eventually a decline in RAGE expression in pancreatic islets may be associated with impaired insulin secretion (Forbes, Soderlund et al. 2011). Each of these rodent models suggests, however, that more RAGE expression is associated with greater insulin expression and secretion, given that chronic models show a loss of insulin secretory capacity in the context of less RAGE expression. However, in our human population circulating isoforms of RAGE were increased in association with lower fasting and lower 2 hour plasma glucose levels during OGTT. In addition, acute insulin secretion on IVGTT was also negatively associated with esRAGE concentrations. Although surprising, these changes agree with the higher insulin secretion seen with increasing AGE concentrations observed in our overweight human population. The specific mechanisms by which this occurs however, remains to be fully delineated. 


\section{Conclusion}

Taken together, these studies suggest that there is a relationship between circulating advanced glycation end products and insulin secretion in healthy humans, which could influence glycaemic control, but appeared to be independent of insulin resistance in this population. The association between AGEs and insulin secretion is likely to involve modulation of the AGE receptor, RAGE isoforms given their negative relationship with insulin secretion in the present study, although this remains to be fully ascertained in human interventional studies. Therefore changes in circulating AGE modified proteins and soluble RAGE as a result of numerous stressors such as consumption of processed diets, which may be high in AGE content, obesity and renal impairment may be risk factors for the development of early insulin hypersecretion and progressively, insulin secretory defects. 
Indeed, changes in circulating and tissue AGE accumulation and/or their receptor RAGE, could therefore be risk factors for the development of type 2 diabetes per se which should be the subject of future studies in larger clinical cohorts. 


\section{Conflict of Interest Statement}

There are no conflicts of interest, which exist for the data presented within this manuscript.

\section{Acknowledgements}

We wish to thank all volunteers for their participation in the study. We wish to also thank the Nutrition Department at the Alfred Hospital, Melbourne Australia and Dr. Malcolm Riley, Ms. Mariee Grima, Mr Donovan Martin, at Baker IDI.

This research was also in part supported by the National Health and Medical Research Council of Australia, Victorian Government's Operational Infrastructure Support Program, Bennelong Foundation, Cardiovascular lipid grant,; Diabetes Australia Research Trust Millennium Award.

BdC, JMF, BAK, MEC, MPS are all fellows of the NHMRC of Australia. MTC is a Roche/ANZSN Career Development 
Fellow. KCS is supported by a Viertel Diabetes Australia Research Trust Fellowship and JGL is supported by the National Heart Foundation of Australia and Cardiac Society of Australia and New Zealand.

No sponsor had any role in the study design, data collection, data analysis, data interpretation, or writing of the manuscript. 
TABLE 1: Anthropometric and metabolic parameters of study population

\begin{tabular}{l|l|ll}
\hline & All & Female & Male \\
& $N=44$ & $N=17$ & $N=27$ \\
\hline Age (years) & $30 \pm 10$ & $30 \pm 10$ & $31 \pm 10$ \\
Body Weight (kg) & $84 \pm 16$ & $74 \pm 12$ & $90 \pm 16^{*}$ \\
Fasting plasma glucose & $4.8 \pm 0.6$ & $4.5 \pm 0.6$ & $4.9 \pm 0.5$ \\
(mmol/L) & & $5.2 \pm 1.5$ & $5.1 \pm 1.5$ \\
2 hour plasma glucose & $5.1 \pm 1.5$ & & \\
OGTT (mmol/L) & & $10.9 \pm 4.6$ & 7.8 \\
Insulin sensitivity - M & $9.0 \pm 4.2$ & & \\
(mg/kg/min) & & & \\
Insulin secretion AUC 3- & $137 \pm 68$ & & \\
5 mins IVGTT(mU/L) & & & \\
Alkaline phosphatase & $68 \pm 21$ & & \\
(U/L) & & & \\
\hline
\end{tabular}




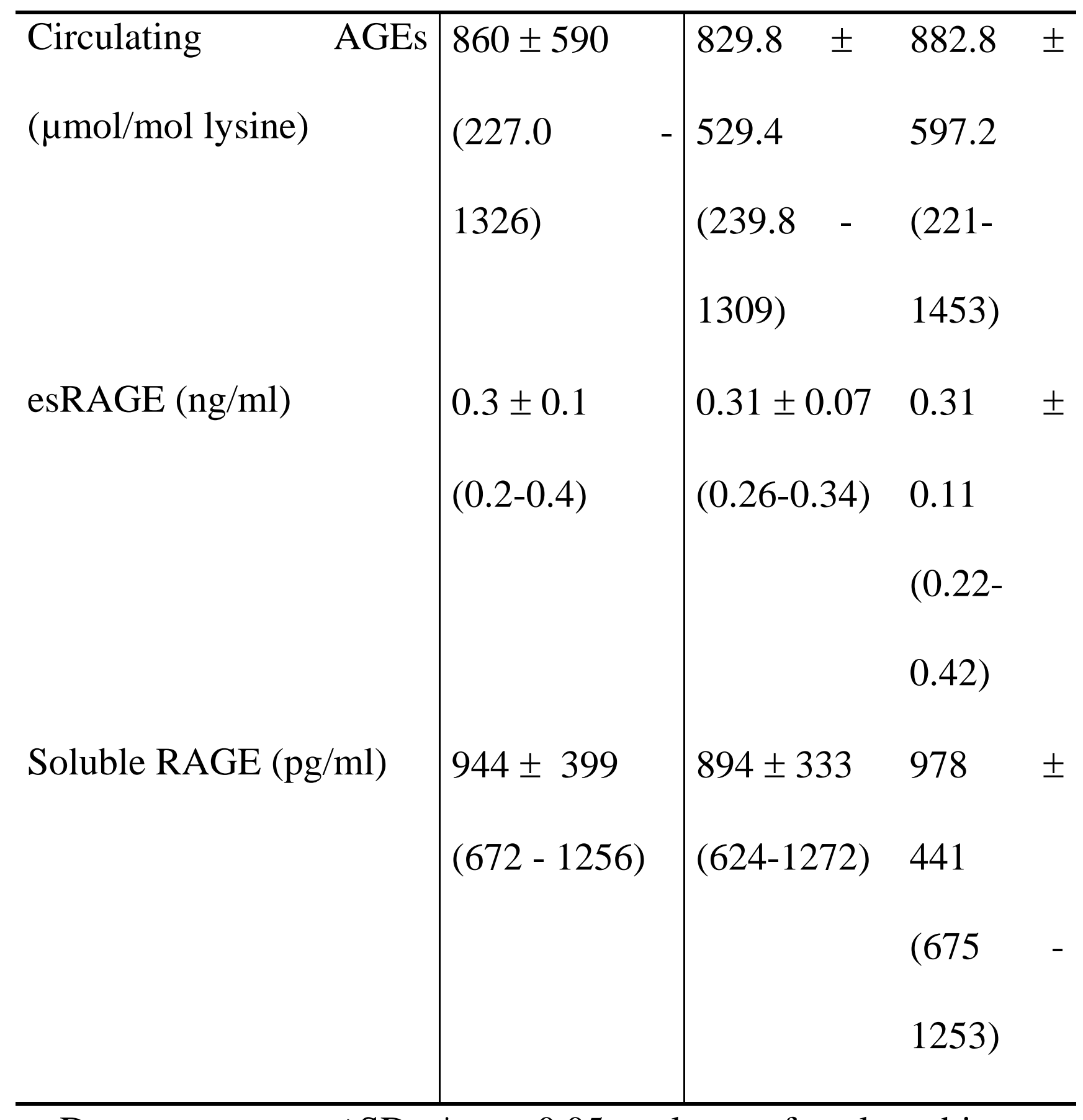

Data are means $\pm \mathrm{SD}$, ${ }^{*} p<0.05$ male vs. female subjects Circulating AGEs, esRAGE and soluble RAGE are represented as means \pm SD range is included in the brackets 
Table 2: Pearson correlation coefficients. Relationships between circulating AGEs and 
metabolic parameters in human participants. $\mathrm{N}=44$ (apart from insulin secretion $(n=22)$.

$* P<0.05 ; * * P<0.01$

\begin{tabular}{l|ccc}
\hline & Serum & sRAGE & esRAGE \\
& AGEs & & \\
\hline Fasting glucose & -0.19 & $-0.36^{*}$ & -0.20 \\
2 hour glucose & $-0.31^{*}$ & $-0.39^{* *}$ & $-0.34^{*}$ \\
(OGTT) & & & \\
Insulin & 0.21 & -0.03 & 0.13 \\
sensitivity & & & \\
Insulin & $0.43^{*}$ & -0.28 & $-0.33^{*}$ \\
secretion & & & \\
(IVGTT AUC & & & \\
3-5 mins)
\end{tabular}




\section{References}

Beisswenger, B. G., E. M. Delucia, N. Lapoint, R. J. Sanford and P. J. Beisswenger (2005). "Ketosis leads to increased methylglyoxal production on the Atkins diet." Ann N Y Acad Sci 1043: 201-210.

Bierhaus, A., K. M. Haslbeck, P. M. Humpert, B. Liliensiek, T. Dehmer, M. Morcos, A. A. Sayed, M. Andrassy, S. Schiekofer, J. G. Schneider, J. B. Schulz, D. Heuss, B. Neundorfer, S. Dierl, J. Huber, H. Tritschler, A. M. Schmidt, M. Schwaninger, H. U. Haering, E. Schleicher, M. Kasper, D. M. Stern, B. Arnold and P. P. Nawroth (2004). "Loss of pain perception in diabetes is dependent on a receptor of the immunoglobulin superfamily." J Clin Invest 114(12): 17411751.

Birlouez-Aragon, I., G. Saavedra, F. J. Tessier, A. Galinier, L. Ait-Ameur, F. Lacoste, C. N. Niamba, N. Alt, V. Somoza and J. M. Lecerf (2010). "A diet based on high-heat-treated foods promotes risk factors for diabetes mellitus and cardiovascular diseases." Am J Clin Nutr 91(5): 1220-1226.

Chiavaroli, V., E. D'Adamo, C. Giannini, T. de Giorgis, S. De Marco, F. Chiarelli and A. Mohn (2012). "Serum levels of receptors for advanced glycation end products in normalweight and obese children born small and large for gestational age." Diabetes Care 35(6): 1361-1363.

Cordain, L., S. B. Eaton, A. Sebastian, N. Mann, S. Lindeberg, B. A. Watkins, J. H. O'Keefe and J. Brand-Miller (2005). "Origins and evolution of the Western diet: health implications for the 21st century." Am J Clin Nutr 81(2): 341354.

Coughlan, M. T. and J. M. Forbes (2011). "Temporal increases in urinary carboxymethyllysine correlate with 
albuminuria development in diabetes." Am J Nephrol 34(1): 9-17.

Coughlan, M. T., F. Y. Yap, D. C. Tong, S. Andrikopoulos, A. Gasser, V. Thallas-Bonke, D. E. Webster, J. Miyazaki, T. W. Kay, R. M. Slattery, D. M. Kaye, B. G. Drew, B. A. Kingwell, S. Fourlanos, P. H. Groop, L. C. Harrison, M. Knip and J. M. Forbes (2011). "Advanced glycation end products are direct modulators of beta-cell function." Diabetes 60(10): 2523-2532.

Forbes, J. M., S. P. Cowan, S. Andrikopoulos, A. L. Morley, L. C. Ward, K. Z. Walker, M. E. Cooper and M. T. Coughlan (2013). "Glucose homeostasis can be differentially modulated by varying individual components of a western diet." $\underline{\mathrm{J} \text { Nutr }}$ Biochem.

Forbes, J. M., J. Soderlund, F. Y. Yap, M. Knip, S. Andrikopoulos, J. Ilonen, O. Simell, R. Veijola, K. C. Sourris, M. T. Coughlan, C. Forsblom, R. Slattery, S. T. Grey, M. Wessman, H. Yamamoto, A. Bierhaus, M. E. Cooper and P. H. Groop (2011). "Receptor for advanced glycation endproducts (RAGE) provides a link between genetic susceptibility and environmental factors in type 1 diabetes." Diabetologia 54(5): 1032-1042.

Hagiwara, S., T. Gohda, M. Tanimoto, T. Ito, M. Murakoshi, I. Ohara, T. Yamazaki, M. Matsumoto, S. Horikoshi, K. Funabiki and Y. Tomino (2009). "Effects of pyridoxamine (K-163) on glucose intolerance and obesity in high-fat diet C57BL/6J mice." Metabolism 58(7): 934-945.

Hellwig, M., S. Geissler, A. Peto, I. Knutter, M. Brandsch and T. Henle (2009). "Transport of free and peptide-bound pyrraline at intestinal and renal epithelial cells." J Agric Food Chem 57(14): 6474-6480. 
Henle, T. (2005). "Protein-bound advanced glycation endproducts (AGEs) as bioactive amino acid derivatives in foods." Amino Acids 29(4): 313-322.

Hofmann, S. M., H. J. Dong, Z. Li, W. Cai, J. Altomonte, S. N. Thung, F. Zeng, E. A. Fisher and H. Vlassara (2002). "Improved insulin sensitivity is associated with restricted intake of dietary glycoxidation products in the $\mathrm{db} / \mathrm{db}$ mouse." Diabetes 51(7): 2082-2089.

Kaneto, H., J. Fujii, T. Myint, N. Miyazawa, K. N. Islam, Y. Kawasaki, K. Suzuki, M. Nakamura, H. Tatsumi, Y. Yamasaki and N. Taniguchi (1996). "Reducing sugars trigger oxidative modification and apoptosis in pancreatic beta-cells by provoking oxidative stress through the glycation reaction." Biochem J 320 ( Pt 3): 855-863.

Matsuoka, T., Y. Kajimoto, H. Watada, H. Kaneto, M. Kishimoto, Y. Umayahara, Y. Fujitani, T. Kamada, R. Kawamori and Y. Yamasaki (1997). "Glycation-dependent, reactive oxygen species-mediated suppression of the insulin gene promoter activity in HIT cells." J Clin Invest 99(1): 144150.

Miyata, T., Y. Ueda, K. Horie, M. Nangaku, S. Tanaka, C. van Ypersele de Strihou and K. Kurokawa (1998). "Renal catabolism of advanced glycation end products: the fate of pentosidine." Kidney Int 53(2): 416-422.

Nin, J. W., A. Jorsal, I. Ferreira, C. G. Schalkwijk, M. H. Prins, H. H. Parving, L. Tarnow, P. Rossing and C. D. Stehouwer (2011). "Higher plasma levels of advanced glycation end products are associated with incident cardiovascular disease and all-cause mortality in type 1 diabetes: a 12-year follow-up study." Diabetes Care 34(2): 442-447.

Penfold, S. A., M. T. Coughlan, S. K. Patel, P. M. Srivastava, K. C. Sourris, D. Steer, D. E. Webster, M. C. Thomas, R. J. 
MacIsaac, G. Jerums, L. M. Burrell, M. E. Cooper and J. M. Forbes (2010). "Circulating high-molecular-weight RAGE ligands activate pathways implicated in the development of diabetic nephropathy." Kidney Int 78(3): 287-295.

Pratley, R. E. and C. Weyer (2002). "Progression from IGT to type 2 diabetes mellitus: the central role of impaired early insulin secretion." Curr Diab Rep 2(3): 242-248.

Puddu, A., R. Sanguineti, A. Durante and G. L. Viviani (2012). "Pioglitazone attenuates the detrimental effects of advanced glycation end-products in the pancreatic beta cell line HIT-T15." Regul Pept 177(1-3): 79-84.

Riboulet-Chavey, A., A. Pierron, I. Durand, J. Murdaca, J. Giudicelli and E. Van Obberghen (2006). "Methylglyoxal impairs the insulin signaling pathways independently of the formation of intracellular reactive oxygen species." Diabetes 55(5): 1289-1299.

Rizkalla, S. W., M. Laromiguiere, M. Champ, F. Bruzzo, J. Boillot and G. Slama (2007). "Effect of baking process on postprandial metabolic consequences: randomized trials in normal and type 2 diabetic subjects." Eur J Clin Nutr 61(2): 175-183.

Sandu, O., K. Song, W. Cai, F. Zheng, J. Uribarri and H. Vlassara (2005). "Insulin resistance and type 2 diabetes in high-fat-fed mice are linked to high glycotoxin intake." Diabetes 54(8): 2314-2319.

Schmidt, A. M., S. D. Yan, J. L. Wautier and D. Stern (1999). "Activation of receptor for advanced glycation end products: a mechanism for chronic vascular dysfunction in diabetic vasculopathy and atherosclerosis." Circ Res 84(5): 489-497. Sebekova, K., V. Somoza, M. Jarcuskova, A. Heidland and L. Podracka (2009). "Plasma advanced glycation end products are decreased in obese children compared with lean controls." Int J Pediatr Obes 4(2): 112-118. 
Sourris, K. C., J. G. Lyons, M. P. de Courten, S. L. Dougherty, D. C. Henstridge, M. E. Cooper, M. Hage, A. Dart, B. A. Kingwell, J. M. Forbes and B. de Courten (2009). "c-Jun NH2-terminal kinase activity in subcutaneous adipose tissue but not nuclear factor-kappaB activity in peripheral blood mononuclear cells is an independent determinant of insulin resistance in healthy individuals." Diabetes 58(6): 1259-1265.

Sourris, K. C., J. G. Lyons, S. L. Dougherty, V. Chand, N. E. Straznicky, M. P. Schlaich, M. T. Grima, M. E. Cooper, B. A. Kingwell, M. P. de Courten, J. M. Forbes and B. de Courten (2013). "Plasma advanced glycation end products (AGEs) and NF-kappaB activity are independent determinants of diastolic and pulse pressure." Clin Chem Lab Med: 1-10.

Stam, F., C. G. Schalkwijk, C. van Guldener, P. M. ter Wee and C. D. Stehouwer (2006). "Advanced glycation endproduct peptides are associated with impaired renal function, but not with biochemical markers of endothelial dysfunction and inflammation, in non-diabetic individuals." Nephrol Dial Transplant 21(3): 677-682.

Stirban, A., P. Kotsi, K. Franke, U. Strijowski, W. Cai, C. Gotting and D. Tschoepe (2012). "Acute Macrovascular Dysfunction in Patients With Type 2 Diabetes Mellitus Induced by Ingestion of Advanced Glycated Betalactoglobulins." Diabetes Care.

Sullivan, C. M., T. S. Futers, J. H. Barrett, B. I. Hudson, M. S. Freeman and P. J. Grant (2005). "RAGE polymorphisms and the heritability of insulin resistance: the Leeds family study." Diab Vasc Dis Res 2(1): 42-44.

Tian, J., A. M. Avalos, S. Y. Mao, B. Chen, K. Senthil, H. Wu, P. Parroche, S. Drabic, D. Golenbock, C. Sirois, J. Hua, L. L. An, L. Audoly, G. La Rosa, A. Bierhaus, P. Naworth, A. Marshak-Rothstein, M. K. Crow, K. A. Fitzgerald, E. Latz, P. 
A. Kiener and A. J. Coyle (2007). "Toll-like receptor 9dependent activation by DNA-containing immune complexes is mediated by HMGB1 and RAGE." Nat Immunol 8(5): 487496.

Uribarri, J., W. Cai, M. Ramdas, S. Goodman, R. Pyzik, X. Chen, L. Zhu, G. E. Striker and H. Vlassara (2011). "Restriction of advanced glycation end products improves insulin resistance in human type 2 diabetes: potential role of AGER1 and SIRT1." Diabetes Care 34(7): 1610-1616.

Uribarri, J., A. Stirban, D. Sander, W. Cai, M. Negrean, C. E. Buenting, T. Koschinsky and H. Vlassara (2007). "Single oral challenge by advanced glycation end products acutely impairs endothelial function in diabetic and nondiabetic subjects." Diabetes Care 30(10): 2579-2582.

Vaaler, S., K. F. Hanssen and O. Aagenaes (1984). "The effect of cooking upon the blood glucose response to ingested carrots and potatoes." Diabetes Care 7(3): 221-223.

Vlassara, H., L. J. Striker, S. Teichberg, H. Fuh, Y. M. Li and M. Steffes (1994). "Advanced glycation end products induce glomerular sclerosis and albuminuria in normal rats." Proc Natl Acad Sci U S A 91(24): 11704-11708.

Weyer, C., P. A. Tataranni, C. Bogardus and R. E. Pratley (2001). "Insulin resistance and insulin secretory dysfunction are independent predictors of worsening of glucose tolerance during each stage of type 2 diabetes development." Diabetes Care 24(1): 89-94.

Yamamoto, Y., I. Kato, T. Doi, H. Yonekura, S. Ohashi, M. Takeuchi, T. Watanabe, S. Yamagishi, S. Sakurai, S. Takasawa, H. Okamoto and H. Yamamoto (2001). "Development and prevention of advanced diabetic nephropathy in RAGE-overexpressing mice." $\mathrm{J}$ Clin Invest 108(2): 261-268. 
Zong, H., A. Madden, M. Ward, M. H. Mooney, C. T. Elliott and A. W. Stitt (2010). "Homodimerization is essential for the receptor for advanced glycation end products (RAGE)mediated signal transduction." J Biol Chem 285(30): 2313723146.

Table 1 Rodent physiological and metabolic parameters at week 4.

Plasma glucose and glycated hemoglobin are included as measures of glycaemic control at the study end point (4 weeks).

\begin{tabular}{l|cc}
\hline & High AGE & Low AGE \\
\hline $\begin{array}{l}\text { Fasting Plasma Glucose } \\
\text { (mmol/L) }\end{array}$ & $7.0 \pm 0.8$ & $7.1 \pm 1.0$ \\
$\begin{array}{l}\text { Glycated Haemoglobin } \\
(\%)\end{array}$ & $3.1 \pm 0.3$ & $3.0 \pm 0.7$ \\
Body Weight (g) & $458 \pm 22$ & $439 \pm 31$ \\
Plasma AGEs & $253 \pm 74$ & $250 \pm 80$ \\
$(\mu \mathrm{mol} /$ mol lysine) & & \\
\hline
\end{tabular}


Table 2: Pearson correlation coefficients. Relationships between circulating AGEs and metabolic parameters in human participants. $\mathrm{N}=44$ (apart from insulin secretion $(\mathrm{n}=23)$. $* P<0.05 ; * * P<0.01$

\begin{tabular}{|c|c|c|c|}
\hline & $\begin{array}{l}\text { Serum } \\
\text { AGEs }\end{array}$ & SRAGE & esRAGE \\
\hline Fasting glucose & -0.19 & $-0.36^{*}$ & -0.20 \\
\hline 2 hour glucose & $-0.31 *$ & $-0.39 * *$ & $-0.34 *$ \\
\hline Insulin & 0.21 & -0.03 & 0.13 \\
\hline \multicolumn{4}{|l|}{ sensitivity } \\
\hline Insulin & $0.43^{*}$ & -0.28 & $-0.33 *$ \\
\hline
\end{tabular}


secretion 
Figure 1: Insulin secretion and sensitivity following short term infusion of AGEs in rats. Groups of Sprague Dawley rats ( $\mathrm{n}=10 /$ group) were infused with $20 \mathrm{mg} / \mathrm{kg} / \mathrm{day}$ of AGERSA (High AGE) or RSA (low AGE) via subcutaneous minipump for 1 month. a-c Intravenous glucose tolerance testing parameters a) Plasma glucose concentrations; b) Plasma insulin concentrations; c) glucose disposal rate; d) HOMA-IR; e) AUC insulin:AUC glucose; f) Proinsulin gene expression; g) Islet AGE content; h) Islet RAGE content; i-k Islet proliferation using PCNA immunohistochemistry, g) Quantification; Representative Photomicrographs (x200) of h) Low AGE i) High AGE groups. $* P<0.05$ vs Low AGE group. 

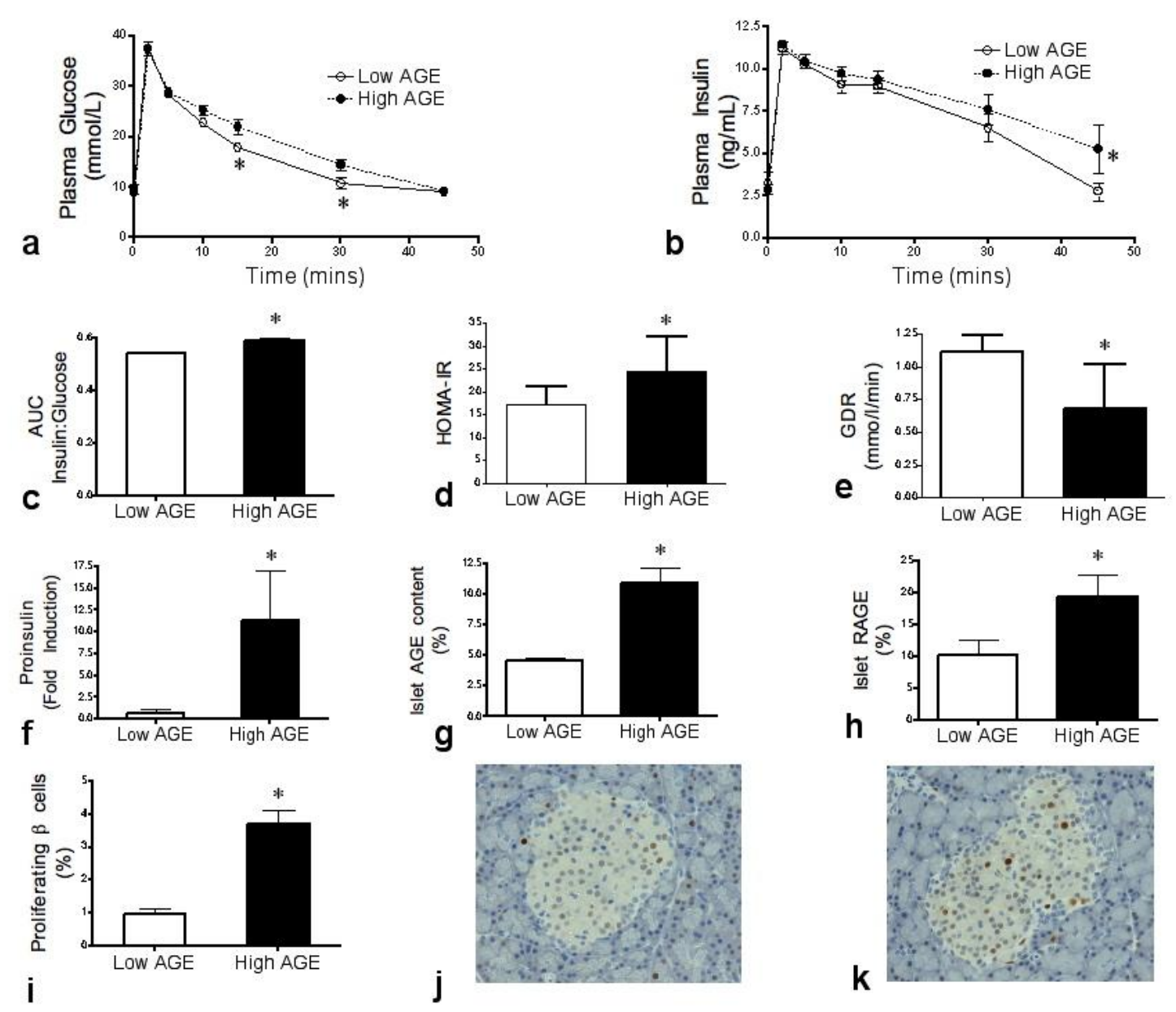


\section{University Library}

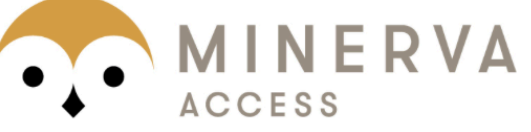

A gateway to Melbourne's research publications

Minerva Access is the Institutional Repository of The University of Melbourne

Author/s:

Forbes, JM;Sourris, KC;de Courten, MPJ;Dougherty, SL;Chand, V;Lyons, JG;Bertovic, D;Coughlan, MT;Schlaich, MP;Soldatos, G;Cooper, ME;Straznicky, NE;Kingwell, BA;de Courten, B

Title:

Advanced glycation end products (AGEs) are cross-sectionally associated with insulin secretion in healthy subjects

Date:

2014-02-01

Citation:

Forbes, J. M., Sourris, K. C., de Courten, M. P. J., Dougherty, S. L., Chand, V., Lyons, J. G., Bertovic, D., Coughlan, M. T., Schlaich, M. P., Soldatos, G., Cooper, M. E., Straznicky, N. E., Kingwell, B. A. \& de Courten, B. (2014). Advanced glycation end products (AGEs) are cross-sectionally associated with insulin secretion in healthy subjects. AMINO ACIDS, 46 (2), pp.321-326. https://doi.org/10.1007/s00726-013-1542-9.

Persistent Link:

http://hdl.handle.net/11343/283273 